\title{
IDENTIDADE NEGRA E ESPAÇO EDUCACIONAL: VOZES, HISTÓRIAS E CONTRIBUIÇÕES DO MULTICULTURALISMO
}

\author{
MARTA DINIZ PAULO DE ASSIS \\ Faculdade de Educação da Universidade Federal do Rio de Janeiro \\ mdpassis@ibest.com.br \\ ANA CANEN \\ Faculdade de Educação da Universidade Federal do Rio de Janeiro \\ acanen@globo.com \\ RESUMO
}

\begin{abstract}
Este artigo analisa processos de construção/reconstrução da identidade negra e suas implicações para a educação, a partir das narrativas e histórias de vida de sujeitos envolvidos em curso de pós-graduação lato sensu sobre "Raça e etnia em educação", desenvolvido em universidade pública brasileira. Três objetivos norteiam o trabalho. De um lado, procura-se avançar subsídios para pensar sobre o multiculturalismo, seus desafios e possibilidades de contribuição para a afirmação identitária a partir da ótica de um marcador adequado - no caso, raça/etnia. De outro, busca-se vislumbrar fatores determinantes na construção da identidade negra, a partir das narrativas dos atores em foco. Por último, tenta-se incorporar o multiculturalismo como estratégia de pesquisa que desafie narrativas dominantes e se construa sobre a pluralidade de vozes e histórias de identidades culturais marginalizadas.

MULTICULTURALISMO-IDENTIDADE-NEGROS-RAÇA
\end{abstract}

\section{ABSTRACT}

BLACKIDENTITY ANDEDUCATIONAL SPACE: VOICES, STORIESANDCONTRIBUTIONSOF MULTICULTURALISM. This article analyzes black-identity building and rebuilding processes, and their implications on education, based on the narratives and life stories of individuals involved in lato sensu post-graduation courses on "Race and ethnicity in education", developed at a Brazilian public university. Three objectives guide this project. On one hand, there is an attempt to advance

Versão preliminar deste artigo foi apresentada na 26ª Reunião da Associação Nacional de PósGraduação e Pesquisa em Educação - ANPEd -, em Poços de Caldas, de 5 a 8 de outubro de 2003. 
in terms of tools to reflect on multiculturalism, its challenges, and possible contribution to an awareness of identity from the point of view of an adequate aspect - race/ethnicity in this case. On the other hand, there is the pursuit of understanding the factors that determine how the black identity is built, based on the narratives of the individuals focused. Finally, there is an attempt to use multiculturalism as a research strategy that challenges dominant narratives and is built on the bases of a number of voices and stories of marginalized cultural identities. MULTICULTURALISM-IDENTITY-BLACK-RACE

A pluralidade cultural da sociedade contemporânea tem sido trazida à tona não só em eventos celebratórios, mas também no interior de imagens chocantes, de intolerância e radicalismos contra aqueles percebidos como "outros", como "diferentes".

Historicamente, não há como negar ou ignorar as relações assimétricas de poder entre as diferentes matrizes culturais e raciais que originaram e dividem o território brasileiro. Nesse horizonte, trata-se de incorporar perspectivas que valorizem a diversidade cultural e reajam contra preconceitos na educação e na formação de professores (Canen, 2002; Canen, Moreira, 200 I; Gomes, Silva, 2002), o que se constitui no foco central do multiculturalismo movimento teórico e político que rompe com a idéia de homogeneidade cultural e busca respostas para incorporar a pluralidade cultural e o desafio à construção das diferenças nos espaços culturais plurais, incluindo a educação (Canen, 2000, 2002; Canen, Arbache, Franco, 2001 ; Canen, Moreira, 200 I; McLaren, 2000; Trindade, 1999). Ainda que tenhamos avançado em formulações teóricas sobre o multiculturalismo, mais investigações ainda são necessárias, particularmente com relação aos potenciais e limites dessa abordagem para a construção da identidade etno-racial nos espaços educativos, bem como no desenvolvimento de caminhos investigativos que tratem dessa construção a partir da ótica daqueles sujeitos cujas identidades têm sido alvo histórico de preconceitos, discriminações e exclusão social.

Buscando contribuir para as reflexões nessa área, este artigo, originário de pesquisa, desenvolvida com o apoio do Conselho Nacional de Desenvolvimento Científico e Tecnológico - CNPq -, analisa processos de construção/ reconstrução da identidade negra e suas implicações para uma educação voltada à valorização das identidades marginalizadas e ao desafio a preconceitos, a partir das narrativas e histórias de vida de sujeitos envolvidos em um curso de pós-graduação lato sensu, desenvolvido em torno do tema "Raça e etnia em educação", em uma universidade pública brasileira. 
Três objetivos norteiam o trabalho. Busca-se primeiramente avançar subsídios para pensar sobre o multiculturalismo, seus desafios e possibilidades de contribuição para a afirmação identitária pela ótica de um marcador de identidade - no caso, raça/etnia. Particularmente, questionam-se possibilidades e limites do multiculturalismo e suas categorias de hibridização e construção identitária plural para a afirmação da identidade negra em espaços educacionais. Em uma segunda perspectiva, o foco sobre as vozes dos sujeitos ligados a esse curso permite vislumbrar, a partir de suas narrativas, fatores determinantes na construção da identidade negra, com possíveis desdobramentos para se pensar em uma educação que a incorpore em seus discursos. Em uma terceira perspectiva, o fato de se trabalhar com vozes plurais para se construir a narrativa da pesquisa vem ao encontro da necessidade de se incorporar o multiculturalismo não só em conteúdos pesquisados, mas como estratégia de pesquisa que se questione a si própria e fuja de discursos dominantes, buscando construir-se sobre a pluralidade de vozes e histórias identitárias. Procura-se, dessa forma, examinar o processo de pesquisa multiculturalmente orientado, ainda foco de poucas investigações entre nós (Canen, Arbache, Franco, 200I).

\section{MULTICULTURALISMO E IDENTIDADE NEGRA: POSSIBILIDADES E TENSÕES}

Como ir além de posturas de denúncia do preconceito contra a identidade negra e incorporar elementos para sua construção positiva, em políticas e práticas educacionais? Esta questão remete à necessidade de compreensão dos mecanismos que participam da construção da identidade negra, de forma a incorporá-los dentro de um quadro educacional que busque ir além da homogeneização cultural ou "cegueira racial", mas que, ao mesmo tempo, não incida em perspectivas meramente folclóricas, em que a diversidade cultural, incluindo a diversidade racial, seja tratada de forma "exótica" e circunstancial.

O foco do multiculturalismo crítico, ou da perspectiva intercultural crítica (Canen, 2000, 2002; Canen, Arbache, Franco, 200 I), tem recaído sobre a categoria identidade, entendida não como algo essencializado, "acabado", definido a priori pela natureza, mas como fruto de construção constante, sempre 
provisória e contingente, nos encontros e nos choques e entrechoques culturais. Nesse sentido, compreender a pluralidade cultural significa compreender a pluralidade de identidades, elas próprias construídas sobre marcadores identitários plurais (Grant, 2000), constituídos de raça, etnia, gênero, classe social, cultura, linguagem e outros determinantes, em interação dinâmica. Isto significa que cada identidade seria constituída na hibridização, isto é, no movimento de articulação e síntese dinâmica entre estes determinantes (Hall, 1997).

Nosso argumento é que, no processo de educação multicultural crítica, cuidados para evitar congelamento identitário podem articular-se às reflexões sobre identidades específicas na tentativa de um equilíbrio dinâmico entre ambas as vertentes. Tal perspectiva visa, justamente, a evitar que se perpetue o que queremos combater: os preconceitos contra aqueles percebidos como "diferentes". Nesse sentido, a luta pela afirmação positiva de certas identidades coletivas pode se beneficiar dos aportes multiculturais, ao mesmo tempo em que se aprofunda nos processos específicos de construção das identidades singulares - como a identidade negra.

\section{APORTES PARA A CONSTRUÇÃO/RECONSTRUÇÃO DA IDENTIDADE NEGRA EM ESPAÇOS EDUCATIVOS}

A identidade negra e sua construção/reconstrução positiva, superadora de discriminações e viabilizadora de práticas curriculares que avancem no reconhecimento e valorização do negro na sociedade, apresenta algumas categorias que se destacam nos discursos e nas discussões a seu respeito: cor, raça e etnia. Entretanto, tensões e ambigüidades apresentam-se nestas categorias, quando tomadas de forma essencializada e estanque, resultando, não raro, no congelamento identitário.

No caso da Fundação Brasileira de Geografia e Estatística - FIBGE -, o padrão utilizado para definir e identificar a população negra parece ser o da cor, entendida como sinônimo de raça, com as tonalidades que variam entre preta, parda, branca e amarela, em contraste com o universo de 136 tonalidades com as mais variadas terminologias, empregadas pela população propriamente dita (Schwarcz, 200 I). Para tornar mais complexa a discussão, é importante notar que a categoria raça - pressuposto da determinação biológica - foi derrubada pelos resultados do projeto Genoma Humano (destinado a mapear e decifrar o códi- 
go genético humano), destituindo-se o conceito de seu status de cientificidade e neutralidade biológica. Entretanto, é interessante notar que alguns autores, tais como Guimarães ( 1999), defendem seu uso e incorporação pelas Ciências Sociais, a partir da compreensão do conceito como categoria socialmente construída e não biologicamente predeterminada. Nesse sentido, similarmente aos pressupostos multiculturais, a idéia da categoria racial como construção remete a um outro patamar: ser negro, ainda que possa ter componentes biológicos, não se esgota nesses componentes, mas é parte de uma construção identitária, em que a identificação racial é também social e culturalmente construída.

A partir dessas considerações, o referido autor entende o racismo como um modo específico de "naturalização" da vida social, que explica diferenças construídas como "naturais". Seguindo esse raciocínio, negros ou brancos podem ser todos aqueles que têm alguma característica que possa (ou não) ser interpretada como configurando a negritude ou a branquidade, dependendo de quem realiza o julgamento. Em visão semelhante, McLaren (2000) propõe, em uma linha multicultural crítica, que se questione também a construção da branquidade, argumentando que se trata de um discurso poderoso, inquestionável até o presente, mas que também não resiste a um processo de desconstrução.

Buscando ir além do determinante raça para a compreensão da construção da identidade negra, alguns autores, como D'Adesky, propõem a categoria etnia como mais fértil para se pensar em sua configuração. Sua definição de etnia é:

...um grupo cujos membros possuem, segundo seus próprios olhos e ante os demais, uma identidade distinta, enraizada na consciência de uma história ou de uma origem comum, simbolizada por uma herança cultural comum que caracteriza uma contribuição ou uma corrente diferenciada de nação (...) baseada em dados objetivos, como uma língua, raça ou religião comum, por vezes um território comum, atual ou passado, ou ainda, na ausência deste, redes de instituições e associações, embora alguns desses dados possam faltar. (D'Adesky, 200l, p. 191)

Desse modo, a etnia aparece, em alguns momentos, como alternativa à raça. Todavia, como critério marcador da identidade negra, situado no âmbito cultural, sem vínculos com traços fenotípicos, tal critério tem gerado polêmicas. Isso porque ainda que se reconheça sua relevância, ele pode levar a uma ênfase demasiada na dimensão cultural. 
○ que se destaca nessas discussões é a tensão, já detectada no debate multicultural, entre aspectos específicos ligados a determinantes biológicos e outros mais abrangentes que incorporam dimensões culturais de construção da identidade negra. Dentro dessa perspectiva, a africanidade, com seus derivados religiosos, lingüísticos e culturais, é percebida como matriz da construção da identidade negra, apresentando-se como alternativa interessante para o trabalho no espaço educacional.

Castells ( 1999), por sua vez, apresenta considerações instigantes para se pensar a construção da identidade negra. Na perspectiva da multiplicidade, identifica três processos: identidade legitimadora, promovida por instituições sociais dominantes, reforçando uma atitude de submissão dos sujeitos; identidade de resistência, configurada em atores em condição social desfavorecida, que apresentam resistências ao projeto dominador, mas ainda não chegam a propor formas positivas de construção identitária; e a identidade de projeto, na qual os atores, com base nos materiais culturais disponíveis, constroem novas identidades, redefinem seu local social e buscam mudanças na estrutura social.

Dentro do quadro das especificidades da construção identitária, a identidade negra oferece particular interesse no cenário da sociedade brasileira, marcada pelo tratamento histórico desigual ao negro e por medidas políticas de ação afirmativa corretivas recentes, como a reserva de cotas para negros e pardos no sistema público universitário, justificando sua relevância nas discussões multiculturais sobre construção identitária.

Conforme nosso argumento, a tentativa de trabalho multicultural de valorização cotidiana educacional da identidade negra e de sua incorporação em currículos e práticas educacionais poderia beneficiar-se do mergulho sobre os sentidos da afirmação "ser negro" e sobre as determinações da construção da identidade negra, percebidos nos discursos daqueles que a abraçam em seus debates teóricos e/ou em espaços coletivos de luta por afirmação e representação. Esse é o caso do espaço educacional do curso a ser comentado mais adiante.

É possível avançar na pesquisa multicultural, à medida que vozes plurais são trazidas para o que Denzin e Lincoln (2000) denominam "polifonia" da pesquisa qualitativa, lidando com as redes de subjetividade (Alves, Oliveira, 2002) no cotidiano dos espaços em estudo. Trata-se de movimento em que a "crise da vocalidade" instala-se no ato de pesquisar, entendido como processo 
multicultural, na medida em que o pesquisador é visto como multiculturalmente situado e não como o detentor único da verdade.

\section{VOZES E SUBJETIVIDADES NO CAMPO}

Os sujeitos cujas histórias de vida foram objeto deste estudo inserem-se no espaço educativo inovador do curso de pós-graduação lato sensu que incorporou questões raciais e étnicas no âmbito da educação brasileira como parte do Programa de Educação sobre o Negro na Sociedade Brasileira - Penesb. Os objetivos do curso parecem deixar clara a perspectiva anti-racista defendida pelo multiculturalismo crítico (Canen, 2000, 2002), ainda que o termo multiculturalismo não seja empregado e que a identidade negra não seja explicitada como o móvel principal das preocupações, como se pode verificar:

Objetivos gerais [do curso]: formar quadros de profissionais da educação em cursos regulares, com a necessária competência intelectual e comprometimento político para reduzir a discriminação racial no sistema de ensino e no contexto social mais amplo; criar um corpo de pesquisadores comprometidos com as investigações sobre a população não-branca e suas relações com a educação, objetivando disseminar os conhecimentos produzidos sobre o tema junto à população em geral e em especial junto aos profissionais da educação em formação ou em exercício. Objetivos específicos [do curso]: I. Oferecer a profissionais da educação em exercício em escolas de ensino fundamental e médio oportunidade de adquirir conhecimentos que lhes possibilitem compreender e interferir na situação da população não branca no sistema de ensino, através da revisão de sua prática pedagógica, com vistas a uma pedagogia que promova a real democratização das oportunidades educacionais; 2. Possibilitar a construção de uma ação pedagógica transformadora, face a outras situações de discriminação, em que fatores não raciais são também objeto de segregação de grupos. (Prospecto original do curso em sua primeira versão, em 1995)

Ainda que esses objetivos configurem as intenções iniciais do curso, quando de sua primeira edição, eles certamente nos indicam potenciais multiculturais (Canen, Arbache, Franco, 200 I) para o trabalho educativo que se pretende crítico e antidiscriminatório. Verificar a construção identitária negra, a partir das vivências e vozes dos atores envolvidos naquele espaço, seria re- 
levante à medida que fornecesse pistas para se pensar em movimentos educacionais multiculturais críticos que superassem a denúncia e partissem para a afirmação identitária negra em propostas curriculares transformadoras. Cinco professores, cinco alunos e a coordenadora do curso foram entrevistados em profundidade, sendo que, nos limites deste artigo, focalizaremos trechos dos discursos de quatro professores, duas ex-alunas e da coordenadora, emblemáticos da discussão que conduzimos. Devido ao conteúdo particular e emocional que perpassa os depoimentos, o anonimato dos sujeitos foi garantido, sendo os nomes utilizados fictícios.

Em uma primeira aproximação, percebe-se que a afirmação positiva da identidade negra em termos de cor, raça ou etnia é tensa, comportando contradições e hibridizações que desafiam qualquer idéia de essencialização biológica, o que conduz, ao contrário, para o caráter de construção discursiva dessa identidade. Assim, é interessante apontar para a ambigüidade dessas categorias na definição da identidade negra. Observemos os depoimentos extraídos das histórias de vida de Mara, Josias e Jânio, professores do curso e Sônia e Marly, ex-alunas:

...cor, raça, no registro civil tá que eu sou branca, mas eu sou da cor morena! Minha ascendência racial, pelo que sei, é de grande parte de imigrantes europeus e muitos gaúchos... (Mara)

... a minha cor, eu me considero mestiço, mais puxado para o negro... Minha ascendência racial - sou mestiço, porque meus avós, meu avô era português, minha avó era índia, a outra bisavó tinha marcas de chicote nas costas.... (Josias)

Essa questão da cor é muito relativa, aqui sou identificada como branca, mas, nos Estados Unidos, sou negra, em Santa Catarina, sou negra... Então, se as outras pessoas me enxergam como branca e se eu começo a dizer que sou negra, eu vou virar uma piada para as pessoas. Vão começar a dizer, "essa mulher é doida, ela é branca!". E eu faço isso às vezes, para provocar as pessoas, para ver qual é a reação... Não tenho outra saída, em um país como o nosso, a não ser continuar sendo identificada como branca... Mas tenho ancestrais negros, minha avó era negra, minha família toda é de mestiços... (Sônia)

Muitas vezes ouvi dizer que eu tinha nascido mais "desbotada", que, apesar de ser branca, meu cabelo crespo, meus lábios grossos denunciavam que eu tinha o "pé na cozinha", o que importa é a cor, e como ela é bem clarinha... Também sabia que meu 
pai gostava de sair mais comigo do que com meus irmãos, porque todo mundo dizia que eu havia "puxado" por ele, e ninguém iria ficar comentando sobre a cor dos meus outros irmãos, que eram mais morenos... E isso era engraçado, porque meus irmãos sempre pareceram muito com meu pai e com minha avó paterna, que era negra, mas era como se ninguém notasse as semelhanças, só a cor... (Marly).

É impossível hoje falar em identidade negra desprezando herança religiosa e aí herança religiosa, nesse país, não é só tambor não, tem uma série de outros elementos, porque o toque do tambor tem um significado profundo e muito grande para o negro (...). Aqueles que tocam são mantenedores, preservadores de elementos que falam de uma herança, de uma pátria, de uma vida... (Jânio)

Os trechos acima remetem a algumas considerações que revelam, segundo Guimarães (1999), características de cor e raça que, embora possuindo elementos biológicos, só fazem sentido se compreendidas como construções ideológicas e discursivas. Esse fato fica claro, particularmente, no extrato da história de vida de Marly, em que cabelo crespo, lábios grossos e outras características fenotípicas só adquirem relevo em um contexto específico de discriminação contra aquelas identidades que as possuem, em razão de mecanismos históricos de opressão e injustiça social diante daquelas características. Ao mesmo tempo, ilustram, como no caso de Jânio, a presença de elementos culturais e religiosos, coadunados com a definição de etnia por D'Adesky (200 I), na tentativa de conferir uma identidade de projeto (Castells, 1999) ao que estamos denominando construção positiva da identidade negra.

Em outra perspectiva, o fato de que alguns depoimentos revelam a consciência de um fenótipo branco, em termos do contexto brasileiro, mas demonstram uma identidade que se alinha com a negritude, seja em razão da ancestralidade ou de outros mecanismos emotivos e culturais (como é o caso de Sônia, que prefere ser denominada morena), pode ter desdobramentos no contexto atual das políticas afirmativas e de cursos voltados a identidades específicas. Até que ponto o fenótipo pode caracterizar a identidade negra? Em que medida um curso, voltado à construção positiva da identidade negra, se beneficiaria da exclusão de sujeitos portadores de fenótipos de branquidade, mas identificados com a negritude em sua construção identitária? Essas questões, sem dúvida complexas, intentam tão-somente tensionar pseudoverdades 
e congelamentos identitários (Canen, 2000, 200 I, 2002) no contexto de territórios discursivos por vezes ambíguos e difusos.

Era nosso interesse também detectar, a partir das histórias de vida, as etapas ou influências que teriam sido determinantes na construção da identidade negra. Os depoimentos indicam, grosso modo, três fases pelas quais as identidades negras foram construídas, nas histórias de vida dos sujeitos: uma primeira, em que a discriminação sofrida foi o motor básico da construção identitária; uma segunda, em que a identidade negra é percebida em termos raciais, fenotípicos, ainda que em uma perspectiva nem sempre essencializada (Guimarães, 1999); e uma terceira, em que a dimensão cultural, presente particularmente na categoria etnia (D'Adesky, 200I), parece ser o centro dessa construção identitária negra, geralmente imbuída de uma perspectiva de identidade de projeto (Castells, 1999) mais acentuada nesta do que nas duas primeiras tendências.

A história de vida de leda, fenótipo associado à identidade negra, atuando como professora universitária e coordenadora do Penesb - projeto de sua autoria, que conta com vários colaboradores - ilustra, com clareza, essas perspectivas.

Na minha trajetória familiar, essa questão racial era colocada por minha mãe, que dizia, por exemplo, que "nós somos negros e por isso não podemos cometer erros". Assim, o uniforme da gente ela passava de modo que as professoras pensavam que as blusas eram engomadas porque fazia tudo no capricho, dizendo "vocês têm de se apresentar muito bem,(...) tenham um comportamento decente". Era minha mãe quem colocava essas coisas, mas a clareza da discriminação racial - isso para mim não era percebido porque nossa família - meu pai e minha mãe - eram honestos, eles eram considerados "negros especiais", pois éramos uma família pobre mas de muito prestígio onde morávamos (...) Por isso, a discriminação racial, nesse período da minha vida, não era claramente percebida. (leda)

É interessante notar que a discriminação racial penetra nesse discurso de forma indireta, como assinala leda, sendo que o lugar social ocupado pela família, bem como os adjetivos que a população a ela atribuía, eram como uma espécie de "doação branca". Esses sintomas indiretos da discriminação constituíram uma primeira etapa da construção da identidade negra de leda, ainda em uma perspectiva legitimadora (Castells, 1999), à medida que resultavam numa incorporação acrítica dos valores dominan- 
tes e de suas representações sobre o negro. $O$ discurso de leda, conforme se verá a seguir, mostra que seria mais tarde, durante processos educacionais que envolvem complexas redes de subjetividade cotidianas (Alves, Oliveira, 2002), especificamente na ambiência do Sindicato dos Professores e do Movimento Negro, que ocorreria o "despertar" para a conscientização acerca da discriminação racial, em uma fase denunciatória preconizada pelo multiculturalismo crítico (Canen, 2000, 2002; Canen, Arbache, Franco, 200 I). Nesta fase, identifica-se a construção da identidade de resistência (Castells, 1999), em que leda assume sua identidade negra em oposição à construção das diferenças e dos preconceitos, como se percebe no extrato abaixo:

Então, fiz o mestrado, vim para a universidade, e a minha formação política foi muito a partir do Sindicato dos Professores e do Movimento Negro (...) Neste, encontrei um rapaz e ele me deu um jornal da Sinba - Sociedade Intercâmbio Brasil-África - e, lendo-o, vi o endereço do IPCN - Instituto de Pesquisas das Culturas Negras -, então passei a ir lá. Comecei a ler muito sobre a África recém-independente, Moçambique, Angola, Guiné-Bissau, que estavam conquistando a independência na segunda metade do século passado. E lendo, fui tomando pé das coisas. Aí, a questão racial começou a aflorar de maneira mais forte, ao mesmo tempo em que eu via algum problema em relação ao próprio Movimento Negro, que fez muito, eu inclusive acho que ele deu uma contribuição muito forte para que a gente pudesse ocupar esse espaço que temos hoje na faculdade porque ele fez muitas denúncias, com a questão da discriminação se colocando e se chocando com o poder constituído para impedir que a discriminação avance. Nisso, eu aprendi muito... (leda)

A história de vida narrada por leda levanta importantes considerações no que se refere à identidade negra. Em primeiro lugar, fica claro o aspecto de construção permanente; trata-se de um processo contínuo, que cruza momentos e discursos os mais variados (discursos familiares, discursos políticos, discursos da mídia - no caso, do jornal com que leda teve contato pela primeira vez - e assim por diante), modificando e hibridizando as formas pelas quais essa identidade vai-se constituindo e sendo representada no discurso. Uma segunda ordem de considerações refere-se ao fato de que a cor da pele, a raça e a etnia - categorias que se referem às formas pelas quais se percebe a construção da identidade negra - encontram-se, muitas vezes, imbricadas. 
No caso do discurso de leda, ao referir-se a seu contato com a África, fica clara a predominância da etnia e da cultura (D'Adesky, 200 I) na configuração de uma identidade de projeto da negritude, em uma fase mais atual. De fato, suas considerações sobre o Movimento Negro, embora não explícitas, parecem concentrar-se na discriminação racial como forma de identificação negra. Ainda que louvada e reconhecida como crucial, esta etapa parece ser percebida por leda como necessitando de uma "evolução" para outras formas de percepção da identidade negra, o que indiretamente pode-nos remeter às considerações do multiculturalismo crítico no que diz respeito à hibridização e ao desafio do congelamento identitário. Esse tipo de perspectiva pôde ser observada em um outro extrato do discurso de Alfredo, professor do curso, em que o reconhecimento das "diferenças dentro das diferenças" (Santos, 200 I) é enfatizado, no caso da construção da identidade negra:

Eu entendo que existem culturas negras, pois cultura me levaria a uma identidade monolítica, fechada, o que eu acho que não existe em nenhum lugar do mundo (...) Por exemplo, o que é cultura negra? Você usar cabelo rasta, ou seja, aqueles sinais diacríticos, acionar a cor da pele, gostar de samba, gostar de candomblé? E aquele então que não tem nenhuma devoção religiosa, não usa cabelo rasta, e tem pele escura, a cultura que ele produz no seu dia-a-dia e na sua convivência não é uma cultura negra? (Alfredo)

Uma outra ordem de considerações refere-se à importância dos espaços extra-escolares na construção da identidade negra, ressaltando a importância da manutenção do diálogo entre processos educativos formais e discursos dos movimentos sociais e de Organizações Não Governamentais - ONGs para promover práticas discursivas valorizadoras da pluralidade cultural e desafiadoras das discriminações.

Por último, estávamos interessadas em detectar as representações sobre o multiculturalismo. Uma vez que aqueles sujeitos atuavam em um espaço educacional voltado ao resgate de uma identidade marginalizada e comungavam idéias defendidas pelo multiculturalismo, em que medida haviam ouvido falar nele, consideravam o curso como uma experiência multicultural ou buscavam articulações entre suas categorias e as identidades específicas de que tratavam? Os depoimentos ilustram as idéias e representações sobre o multiculturalismo predominantes em suas visões: 
Confesso que não sou simpático à temática multiculturalista, mas eu sou mais simpático à temática da diversidade cultural, porque acho que ela traduz mais um apelo mundial da necessidade do respeito ao diverso. Então, quando nós fazemos um curso sobre negritude, sobre relações étnicas, que é sobre o negro, na verdade, eu não estou tratando de um curso multicultural, mas de um grupo étnico especificamente. Eu entendo assim, que se você quisesse trabalhar uma experiência multicultural, você teria que trabalhar necessariamente com vários grupo étnicos. Então, não é uma experiência multicultural, ela é um experiência que respeita o direito de um determinado grupo étnico trabalhar a diversidade dentro da cultura, nesse caso, a diversidade étnica do negro. (Jânio)

Eu não sei se consideraria uma experiência multicultural porque não estou a par do que seja multiculturalismo, apesar de estar na moda, eu arriscaria dizer que não, porque até pensei que no curso ouviria falar do indígena também, que é outra cultura marginalizada, e no sentido de ser multi, acho que não, porque a idéia é centrada só na cultura negra, não é? (Sônia)

As respostas indicaram que, em sua maioria, uma visão única do multiculturalismo, mais folclórica e pouco comprometida com a luta pelo desafio às discriminações, ocupava as representações e os discursos dos sujeitos pesquisados. $\bigcirc$ multiculturalismo é entendido, muitas vezes, apenas em razão da "palavra" - múltiplas culturas - e aqueles que acreditam que raça, cor e etnia são a base de sustentação da identidade negra temem que o multiculturalismo promova uma "diluição" das especificidades negras. Ao mesmo tempo, consideram que a concentração em um marcador identitário específico, como raça, não configura uma experiência multicultural.

Tais entendimentos nos levam a considerações. Se, por um lado, a contribuição do multiculturalismo crítico e de suas categorias de identidade, pluralidade e hibridização é relevante no sentido de evitar o "congelamento identitário" em torno de marcadores fixos, que resultam em discriminações, por outro lado, o "perigo" de que esta visão multicultural sobre a hibridização identitária possa "diluir" especificidades de identidades e suas demandas por representação e afirmação torna-se um desafio dessa perspectiva. Em outras palavras: de um lado, o multiculturalismo alerta para a necessidade de não se congelar identidades em torno de marcadores únicos, sob pena de homogeneização das identidades e de perpetuação de preconceitos. Nesse sentido, o 
conceito de hibridização confere uma relativização da construção identitária, fazendo perceber as múltiplas camadas que a perfazem. De outro lado, porém, quando falamos em sujeitos ou identidades coletivas, que justamente se unem em torno de marcadores únicos em espaços específicos, para a requisitar direito a voz e superar discriminações, levanta-se a necessidade de se articularem as considerações multiculturais a outras, voltadas àqueles marcadores singulares.

Entretanto, conforme temos argumentado, em um mundo marcado por ódios e intolerância, abrir as portas para correntes que se propõem a discutir caminhos plurais que possibilitem o resgate de identidades marginalizadas, ao mesmo tempo em que é identificado o campo de lutas dessas identidades em um contexto de desafio a preconceitos e construção das diferenças de um modo mais amplo, pode ser uma possível via de luta, em uma perspectiva articuladora, por espaços sociais, políticos e educacionais menos desiguais e mais valorizadores da pluralidade cultural.

\section{CONCLUSÕES}

As histórias de vida relatadas neste estudo sugerem a confirmação do caráter de construção da identidade negra para além de uma essência biológica aprioristicamente determinada. Tal construção, ela mesma híbrida, apóia-se em depoimentos dos sujeitos do estudo, em elementos discriminatórios, diretos ou indiretos, percebidos desde a mais tenra idade, passando pela resistência à dor com relação a essas discriminações e, muitas vezes (como na história de leda), chegando à constituição de identidades de projeto, nesse caso, para além do preconceito e da luta contra ele, trata-se de buscar caminhos positivos de reconhecimento e de reconstrução da identidade negra.

Os discursos teóricos e os depoimentos coletados sugerem que os caminhos da reconstrução da identidade negra de projeto se constroem por meio de redes de subjetividades, tecidas em espaços de luta e de educação, para além do âmbito oficial, como, por exemplo, em sindicatos, ONGs e movimentos, com destaque para o Movimento Negro. $O$ fato de termos encontrado sujeitos fenotipicamente brancos, mas que se identificam com a negritude é um outro ponto delicado do estudo e, certamente, está longe de atrair respostas prontas, sendo tão-somente mais um ponto de partida para se prosseguir no debate para a construção positiva da identidade negra nos espaços educacionais. 
As tensões e dilemas da construção identitária negra podem representar subsídios para a compreensão da construção identitária de uma forma geral. Resgatar fatores constitutivos da construção da identidade negra, com sua fluidez, mobilidade e complexidade, a partir de sujeitos envolvidos em um espaço educacional voltado a essa finalidade, pode contribuir para as reflexões sobre o problema. $\bigcirc$ temor de que o multiculturalismo poderia diluir as demandas por representação da identidade racial, expresso nos depoimentos analisados, é real, particularmente se o tomarmos em sua versão mais folclórica, pouco problematizadora de preconceitos e da construção das diferenças, como ficou evidenciado nos discursos dos sujeitos do estudo. Entretanto, se articuladas às reflexões mais específicas sobre a identidade marginalizada em questão, apontamos que o multiculturalismo pode ser um contraponto à perpetuação de dualismos como negro e branco, mulher e homem e assim por diante, contribuindo para evitar que se perpetue justamente o que se combate: o preconceito contra o outro, percebido de forma congelada e estanque.

Em uma outra dimensão, os dados indicam a riqueza da pesquisa que se assume como multicultural, procurando tensionar a narrativa com as vozes daquelas identidades em estudo. Tais vozes podem ser trazidas também ao processo de ensino multicultural, e constituir casos a serem debatidos à luz de um projeto de transformação social. As dúvidas e dilemas que cercam o multiculturalismo e o processo de construção da identidade negra não devem ser interpretados como obstáculos ou inconsistências com relação a projetos transformadores. Devem, ao contrário, representar pontos de partida para debates, de forma a progredirmos, cada vez mais, nessa estrada tão corajosamente aberta pelos sujeitos que acreditam na educação como um modo possível de desafiar realidades desiguais instituídas. Suas histórias mostram que caminhos da construção identitária, embora árduos e desafiadores, são prenhes de possibilidades.

\section{REFERÊNCIAS BIBLIOGRÁFICAS}

ALVES, N.; OLIVEIRA, I. B. Uma história da contribuição dos estudos do cotidiano escolar no campo do currículo. In: LOPES, A. C.; MACEDO, E. (orgs.) Currículo: debates contemporâneos. São Paulo: Cortez, 2002. p.78-102. 
CANEN, A. Educação multicultural, identidade nacional e pluralidade cultural: tensões e implicações curriculares. Cadernos de Pesquisa, n. I | I, p. |35- I50, dez. 2000.

Relações raciais e currículo: reflexões a partir do multiculturalismo. Cadernos PNESB, n. 3, p.63-77, 2001 .

Sentidos e dilemas do multiculturalismo: desafios curriculares para o novo milênio. In: LOPES, A. C.; MACEDO, E. (orgs.) Currículo: debates contemporâneos. São Paulo: Cortez, 2002. p. I74- 195.

CANEN, A.; ARBACHE, A.; FRANCO, M. Pesquisando multiculturalismo e educação: o que dizem as dissertações e teses. Educação e Realidade, v.26, n. I, p. |6 | - | 8|, jan./ jun. 2001 .

CANEN, A.; MOREIRA, A. F. B. (orgs.). Ênfases e omissões no currículo. São Paulo: Papirus, 2001 .

CASTELLS, M. O Poder da identidade. São Paulo: Paz e Terra, 1999.

D'ADESKY, J. Pluralismo étnico e multiculturalismo: racismos e anti-racismos no Brasil. Rio de Janeiro: Pallas, 2001.

DENZIN, N.; LINCOLN, Y. (orgs.). Handbook of qualitative research. London: Sage, 2000.

GOMES, N. L.; SILVA, P. B. (orgs.). Experiências étnico-culturais para a formação de professores. Belo Horizonte: Autêntica, 2002.

GRANT, N. Multicultural education in Scotland. Edinburgh: Dunedin Academic Press, 2000.

GUimarães, A. S. A. Racismo e anti-racismo no Brasil. São Paulo: Ed. 34, 1999.

HALL, S. A ldentidade cultural na pós-modernidade. Rio de Janeiro: DP\&A, 1997.

MCLAREN, P. Multiculturalismo revolucionário: pedagogia do dissenso para o novo milênio. Porto Alegre: Artmed, 2000.

SANTOS, B. S. Dilemas do nosso tempo: globalização, multiculturalismo e conhecimento, Educação e Realidade, v.26, n. I, p. 13-32, jan./jun. 2001.

SCHWARCZ, L. M. Racismo no Brasil. São Paulo: Publifolha, 2001.

TRINDADE, A. (org.). Multiculturalismo: mil e uma faces da escola. Rio de Janeiro: DP\&A, 1999.

Recebido em: janeiro 2004

Aprovado para publicação em: junho 2004 